\title{
Ice Creams: A Silent Addiction
}

\author{
Vaishnavi Satheesh* \\ Dietitian, Content Developer, India \\ *Corresponding Author: Vaishnavi Satheesh, Dietitian, Content Developer, India.
}

Received: August 06, 2019; Published: August 23, 2019

DOI: $10.31080 /$ ASNH.2019.03.0425

Do you surprise, if I confess that ice creams as silent addition? Most of us would not. But unfortunately, it is yes! Though melted with its creamy texture and flavor, it poses you some ill health which is really unknown to you. All the foods have pros and cons. Hence, it will be better if you take only the pros by consuming the foods in particular amounts.

Hence, in that way, every one of us from kids to adults is fond of ice creams. You may think of neglecting my thought as you are over attached to its creamy world. But as a dietitian, I would definitely mean to tell you about the consequences of having a habit of ice creams in regular routine diets. As pros, we all are familiar that it aids in weight gaining as its rich in cream and milk and sugar. But I promise you, they are unhealthy calories that are building your body system.

- Obesity being the first risk factor or consequence of ill health, affects majority of children, making them prone to childhood obesity. Some parents are still there who replace unhealthy snacks for healthy ones. They even argue with dietitians and nutritionists about the nutritional value of ice creams as some innovations have been made to incorporate nuts and dry fruits as toppings. It would be best if you start eating those nut toppings alone. As these ice creams are loaded with empty calories from sugars and creams, there is a possibility of these calories getting stored in your adipose tissues. You can say, there is highly super nutritious food milk which is a base for ice creams. But the point is the unhealthy ingredients or unwanted elements in the mixture make the milk too unhealthy. When your body gets used to regular intake, you develop a natural craving towards ice creams. Thus it becomes your addiction. Therefore, prepare yourself to opt for some healthy snacks like fruit salads with nuts and dry fruits as toppings. This will protect you from being obese and makes you safer from inviting many chronic disorders.

- Heart disease is a life threatening disorder of human system. You will be surprised to note that an ice cream contains about $40 \mathrm{gms}$ of saturated fats. These saturated fats are the real culprits in heart disease cases. Increasing the triglyceride and cholesterol levels in the blood, these ice creams may make the person prone to suffer from heart disorders. Though these levels may become normal after some times of eating an ice cream, constant craving and constant consumption of cool ice creams loaded with saturated fats may render a heart illness. Hence it is always better to limit the ice creams.

- Reduction of cognitive skill are very common among the persons especially kids, who have ice creams in their regular meals. These ice creams as with excessive chillness, may stop the action of brain, thus shutting the whole body system for a minimum of 10 seconds. This usually happens when the extreme chillness touches the upper palate of our mouth. I guess, many of you can connect with me. However, this may be recovered to its original action within 20 seconds. Regular addiction over ice creams may worsen the brain power as it gets shut many times. Hence, be limit in your quantity.

- Slow addiction makes a person ill, both mentally and physically. Yes! Similar to drug addiction or any alcohol addiction, this ice cream addiction is too dangerous. Loaded with unhealthy nutrients and saturated fats, this fills our body with unwanted materials making us unfit for many actions in our life. Consuming a day may chill your day, but when it has become a habit, it is really hot and shaky.

Moreover the flavors are produced using artificial colors and synthetic agents are used while preparing ice creams commercially. All these are artificial and there are chances of getting an infection if any of the mild ingredients is really allergic to the person. As kids are of low immunity, make sure you avoid ice creams in many situations. Rare occasions should be balanced by the smart mommies behind every smarter kid.

However, we should wait for more promising studies to picture the hazards of ice creams on ill health. But, whether good or bad, everything should be in limits so as to enjoy the livelihood. Enjoy your ice creams with certain limits in your intake levels.

\section{Volume 3 Issue 9 September 2019 (C) All rights are reserved by Vaishnavi Satheesh.}

